\section{DYNAMIC RESPONSE CHARACTERISTICS OF THE ACTUAL BUILDING SUBJECTED TO THE INCIDENT WAVES GENERATED FROM AIR GUN IMPACTOR}

\section{エアガン・インパクターからの 入射波動による実存建物の動的 応答特性}

\author{
Ali NIOUSHA $-* 1$ Masato MOTOSAKA $-* 2$ \\ Keywords : \\ Dynamic response characteristics, Air gun impactor, Actual building, \\ Vibration test, Mode decomposition analysis \\ キーワード : \\ 動的応答特性，エアガン・インパクター，実存建物，振動実験，モード分解解 \\ 析
}

ニウシャ アリーー*1＼cjkstart源栄正人 — $* 2$

The dynamic characteristics of a nine-story SRC building were investigated using incident waves generated from impactor machine. It is shown that this device can be right tool to investigate the vibration characteristics of the actual building up to relatively high frequencies range. Horizontal motions as well as rocking and torsional motions were investigated. The pulse like generated wave makes it possible to observe later arrival torsional response, which cannot be obtained in microtremor and vibration test using vibrator. To clarify the modal variations, mode decomposition analysis has been done.

\section{Introduction}

The purpose of this paper is to investigate the dynamic characteristics of the actual building by using incident waves generated from an impactor machine. Different ways exist to get a dynamic load, namely seismic waves, microtremor, vibrator. In this study an impactor machine, which is commonly used in geological reflection survey, is used to generate the dynamic load. The ninestory steel-reinforced concrete (SRC) building of the department of Architecture and Building Science of Tohoku University at Aobayama campus is selected for the study. The building is extensively instrumented for the test to be able clarifying possible motions. The scope of this paper is limited to the significant findings in data analysis. The simulation analysis will be the future extension of this work. The results of this study can be useful for structural reparation of this building, which is planned to start on June 2000.

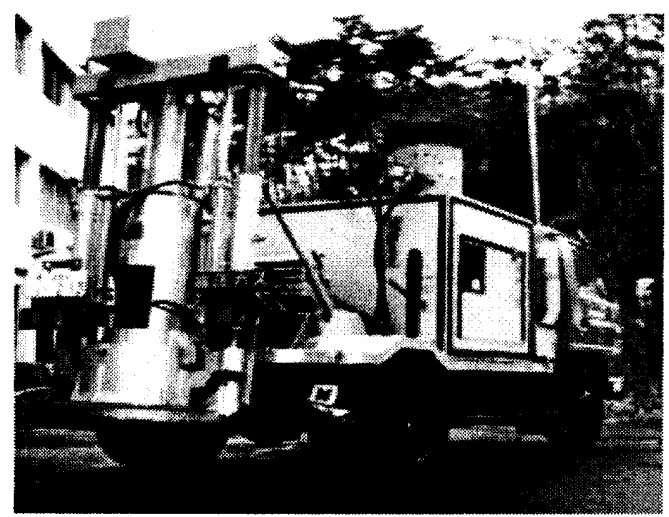

Photo.1 Land Air Gun impactor

2. General descriptions

2.1 Impactor machine

The used impactor is a Land Air Gun type impactor (Photo.1) which is belonging to the Observation Center for Prediction of

*1 Graduate Student, Disaster Control Research Center, Tohoku University

*2 Prof., Disaster Control Research Center, Tohoku University
Earthquake and Volcanic Eruptions of the faculty of science of Tohoku University. The air chamber of the air gun is $6.55 \times 10^{-4} \mathrm{~m}^{3}$ with a maximum operating pressure of $13790 \mathrm{kN} / \mathrm{m}^{2}{ }^{1)}$. The impactor is actually used for geological reflection survey. By this study, it will be shown that this device can be used to investigate the structural response up to relatively high frequency range. The wide frequency

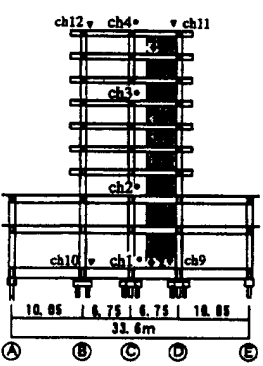

a)Transversal

- Horizontal sensor

$\checkmark$ Vertical sensor

- Seismometer

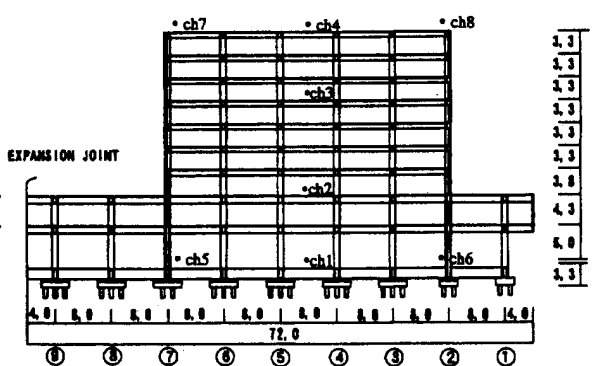

b) Longitudinal
Elevation

A (O)

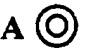

$13.2 \mathrm{~m}$

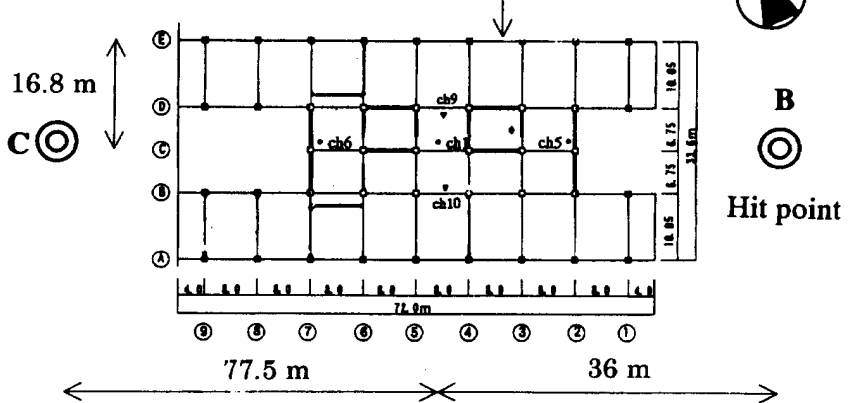

Plan

Fig.1 Layout of the test and observation points.

\footnotetext{
*1 東北大学災害制御研究センター 大学院

(干980-8579 仙台市青葉区新巻字06)

*2 東北大学災害制御研究センタ一教授
} 
range of the generated waves $(0-40 \mathrm{~Hz})$ that can stimulate the higher modes, the pulse-like wave that is similar to the waves produced in a near-source earthquake, and the reproducibility of the waves are the most important points of the usage of this device.

\subsection{Structure, site and instrumentation}

The building of the department of Architecture and Building Science is a nine-story steel-reinforced concrete (SRC) building located at Aobayama campus of Tohoku University. The building was constructed in 1969 on the pile foundation with moment resistant frames and the shear walls to carry the lateral loads. The first 2 floors have a rectangular plan of $72 \times 33.6 \mathrm{~m}$ and from the $3^{\text {rd }}$ floor the section reduces to $40 \times 13.5 \mathrm{~m}$. The building has eccentricity of the stiffness for longitutunal direction which cause the torsinal motion during its dynamic response.

Table 1 Predominant Frequency of the building.

\begin{tabular}{|l|c|c|c|l|}
\cline { 2 - 5 } \multicolumn{1}{c|}{} & $\begin{array}{c}E W \\
\text { Year }\end{array}$ & $\begin{array}{c}N S \\
(\mathrm{~Hz})\end{array}$ & $\begin{array}{c}\text { Torsion } \\
(\mathrm{Hz})\end{array}$ & \multicolumn{1}{|c|}{ Excitation } \\
\hline 1969 & 2.45 & 2.28 & 3.52 & Force vibration \\
\hline 1970 & 2 & 1.85 & $\cdots--$ & $\begin{array}{l}\text { Earthquake } \\
70.9 .14\end{array}$ \\
\hline 1971 & 2.18 & 2.1 & 3.17 & Force vibration \\
\hline $1978^{*}$ & 0.98 & 0.89 & $\cdots$ & $\begin{array}{l}\text { Earthquake } \\
78.6 .12\end{array}$ \\
\hline 1994 & 1.53 & 1.44 & 2.13 & Man vibration \\
\hline $1998^{*}$ & 1.12 & 1.03 & $-\cdots$ & $\begin{array}{l}\text { Earthquake } \\
98.9 .15\end{array}$ \\
\hline 1998 & 1.5 & 1.41 & $\cdots$ & $\begin{array}{l}\text { Microtremor } \\
\text { (after 98.9.15) }\end{array}$ \\
\hline
\end{tabular}

*calculated for data recorded at $1 \mathrm{~F}$ and $9 \mathrm{~F}$.
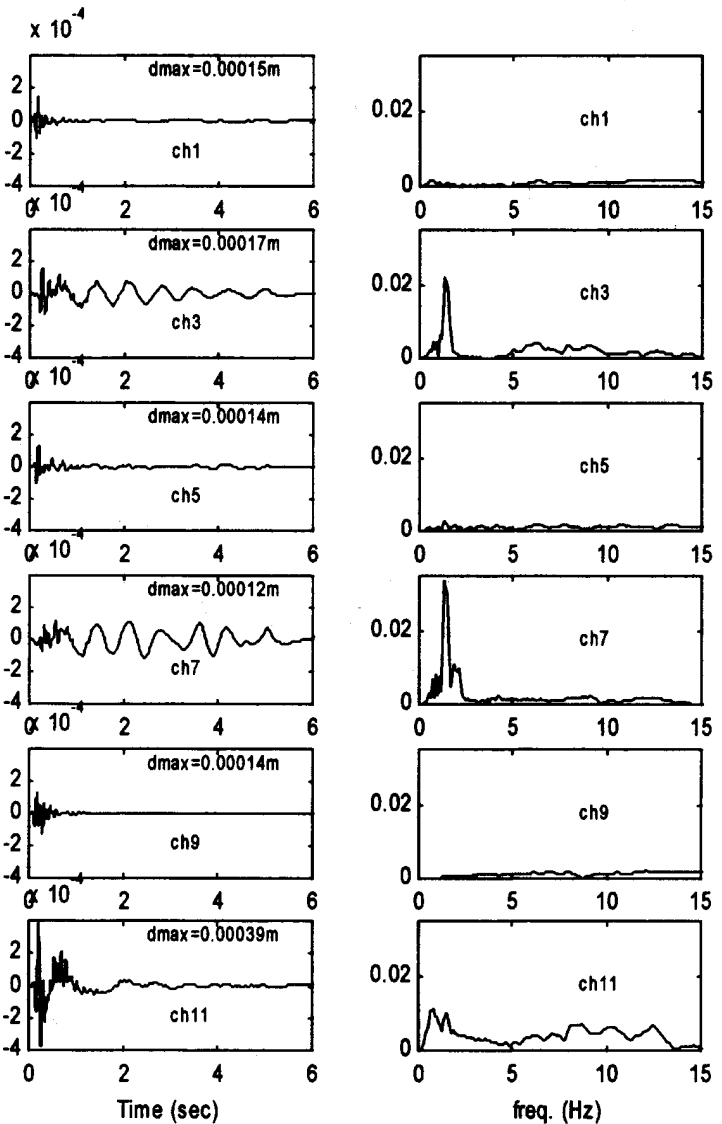

Regarding the soil condition, the sandy gravel surface layers are irregularly stratified on the soft tertiary rock. The average shear wave velocity of the surface layers and soft rock are reported to 250 $\mathrm{m} / \mathrm{s}$ and $500 \mathrm{~m} / \mathrm{s}$, respectively. The surface layer underlying the building had small valley type topography. In the longitudinal direction (EW) of the building, the ground had slop of $6 \%$ and in transversal (NS) direction, a concave-like ground surface existed prior the construction ${ }^{2)}$.

Fig.1 shows the general layout of the test and instrumentation. The impactor hit the ground surface outside of the building at points A, B and C. Case-A was performed to investigate the translation in the NS direction, torsional and rocking motion. The translation in EW direction is investigated from Case-C. Case-B with Case-C are used to check the reciprocity theorem, which will not discuss here. ground motion is briefly discusced in Appendix.

\subsection{Background}

During the last twenty years, several surveys have been done to clarify the dynamic response behavior of this building. The obtained results of the building predominant frequencies are summarized in Table 1. The first test had been done on 1969 just after the completion of the building and the frequency of the fundamental modes were 2.45 and $2.28 \mathrm{~Hz}$ in EW and NS direction ${ }^{3}$, respectively. During the 1970.9.14 earthquake the predominant frequency at the records obtained at nine floor showed a decrease ${ }^{4)}$. On 1971 other test had been done $^{3)}$ and the frequency of the fundamental modes were increased which shows the amplitude dependent characteristics of the building's response. The most significant change in frequency of the fundamental mode occurs during 1978 Miyagiken Oki earthquake, when the structural components like the shear wall of the building hardly damaged. During this earthquake the acceleration record (N\$) at the nine floor exceeds $1 \mathrm{~g}^{4}$ ). Other investigations done after 1978
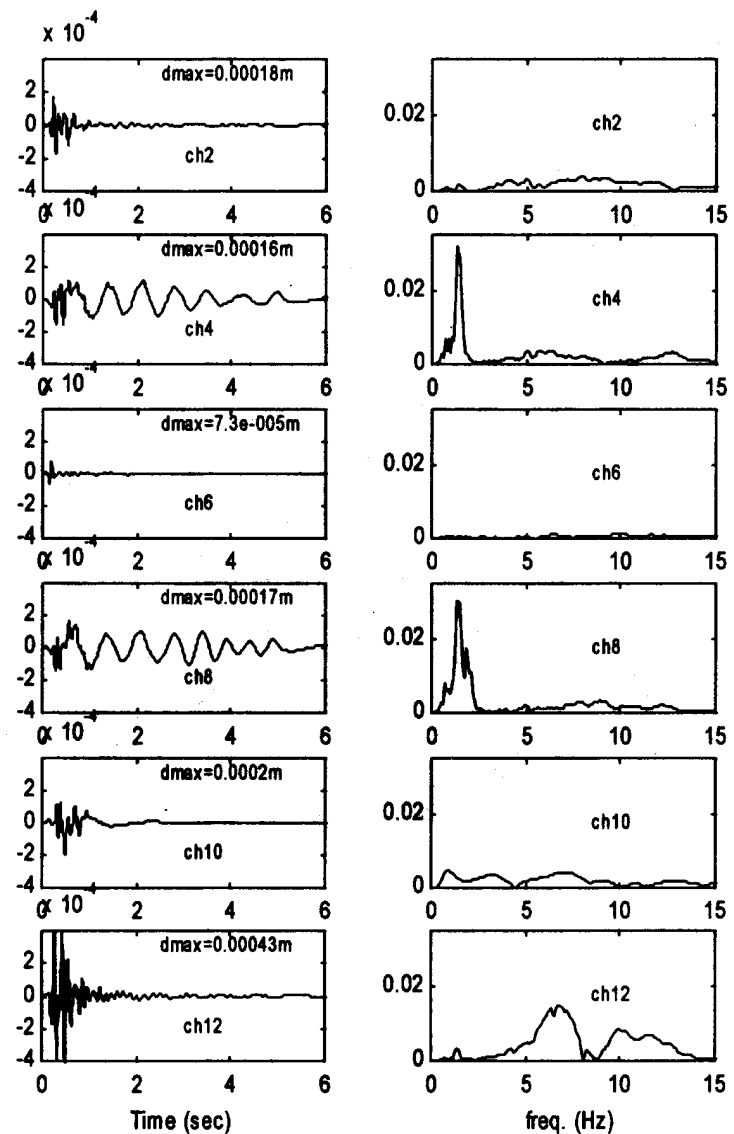

Fig.2 Displacement waveforms and corresponding Fourier spectra in NS direction.(case-A) 

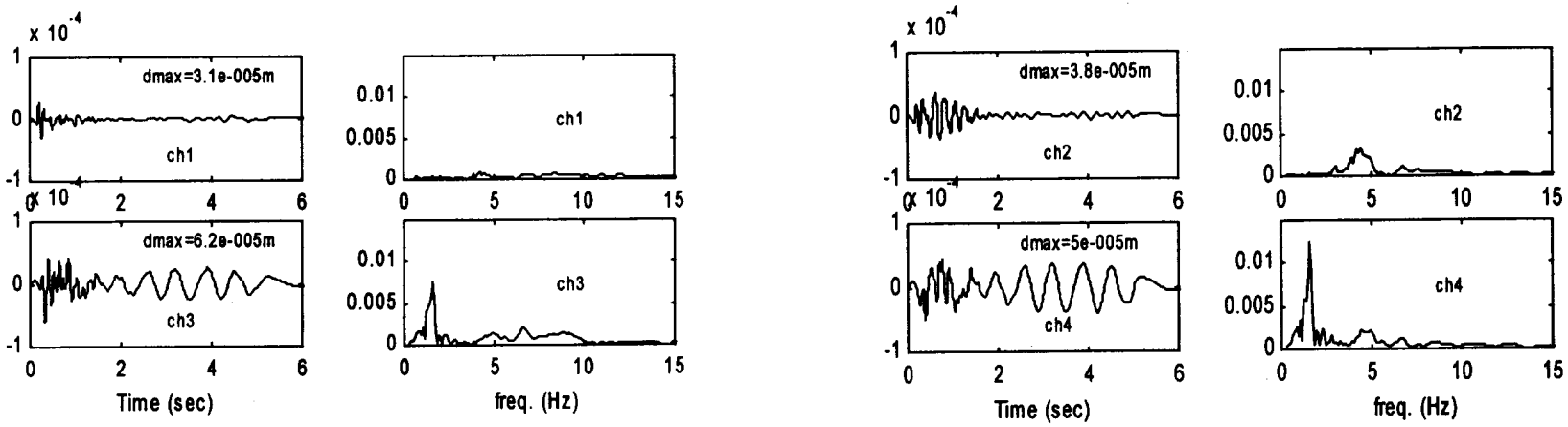

Fig.3 Displacement waveforms and corresponding Fourier spectra in EW direction.(case-C)
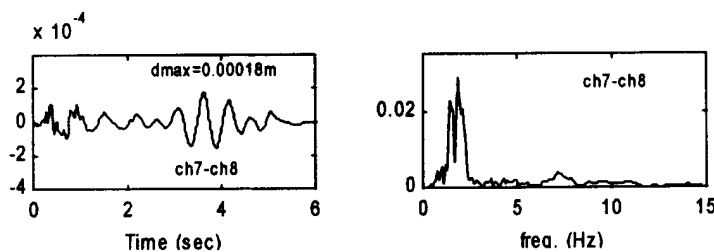

(a) Torsion

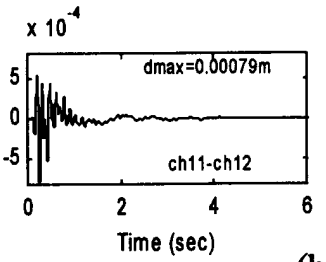

(b) Rocking

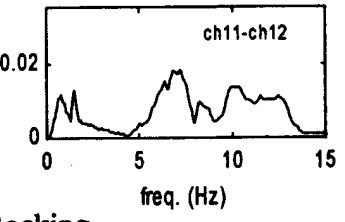

otion.(case-A)
Miyagiken Oki earthquake show higher frequency of the fundamental mode (nearly $1.5 \mathrm{~Hz}(\mathrm{EW})$ and $1.4 \mathrm{~Hz}(\mathrm{NS}))^{5)}$, except during 1998 Miyagiken Nanbu earthquake which are 1.12 and $1.03 \mathrm{~Hz}$ in EW and NS direction ${ }^{6}$. These differences in natural frequency in low and high-level amplitude are due to non-linearty of the damaged structure.

\section{Data processing and analyses}

3.1 Waveforms and Fourier spectra

To reduce the noise effect in the data, stacking technique is applied to data processing. This technique can be performed if the device has reproducibility, which is conformed for this device. Stacking number is 10 times. Digital records are obtained from AD transformation. Then, base line correction, removing of the mean from data, filtering data by using a band-pass causal Butterworth filter of 8 order and range pass of 0.50 to $15 \mathrm{~Hz}$, and stacking have been done. The obtained records are in velocity then integrated to displacement. The displacement waveforms and the corresponding Fourier spectra of the processed records are shown in Figs. 2 and 3.

In NS direction, the obtained record from Ch4 has the dominant frequency at $1.36 \mathrm{~Hz}$, which corresponding to the frequency of the fundamental translation mode. For EW direction's translation the dominant peak is observed at $1.56 \mathrm{~Hz}$. For the $\mathrm{Ch} 7$ and $\mathrm{Ch} 8$, another peak exists around $1.85-1.95 \mathrm{~Hz}$, which can be due the torsional mode. The same peak is observed at this frequency by calculating the spectrum of the relative motions of $\mathrm{Ch} 7$ and $\mathrm{Ch} 8$ (Fig.4a). It must be noted that a later arrival wave exists in the torsional motion of the roof ( $\mathrm{Ch} 7-\mathrm{Ch} 8)$. Without any further investigation, at this stage, it is suggested that this beat phenomenon occur due to the interference of the horizontal and torsional motion. This must be investigated in the time history analysis of the analytical model.

Rocking motion is also observed in the building. From relative motions of vertical records at the roof (Ch11-Ch12), the rocking can be investigated. Fig. $4 \mathrm{~b}$ shows the relative vertical waveforms and corresponding Fourier spectra at this level. The rocking mode's frequency is not clear from the spectrum; therefore further investigations are needed which will discuss in the following part. The coupling effect of rocking and translation, at $1.36 \mathrm{hz}$, is observed in the rocking waveform.

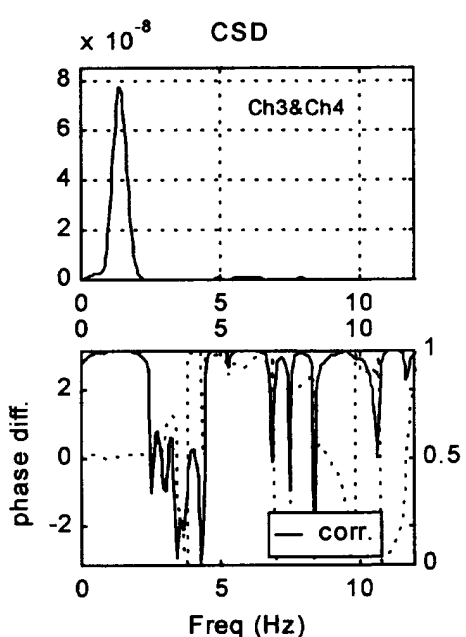

(a)

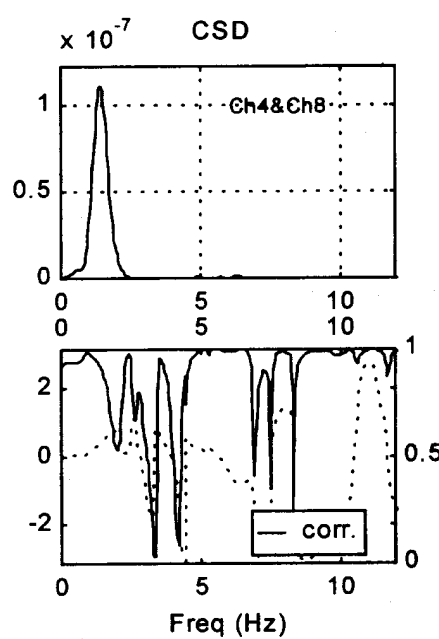

(b)

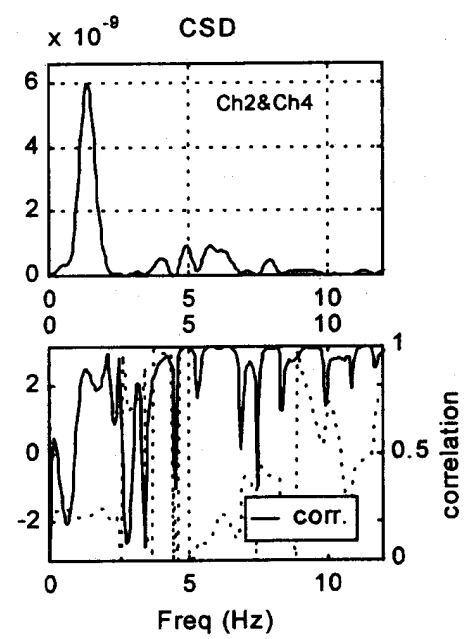

(c)

Fig.5 Cross-spectra and corresponding coherency and phase difference angle (NS). 


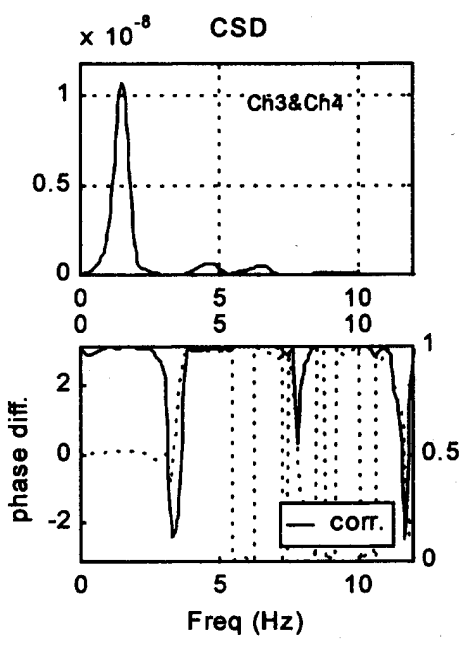

(a)

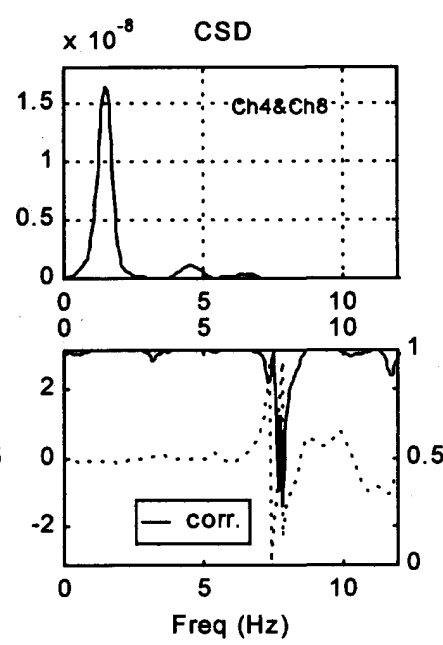

(b)

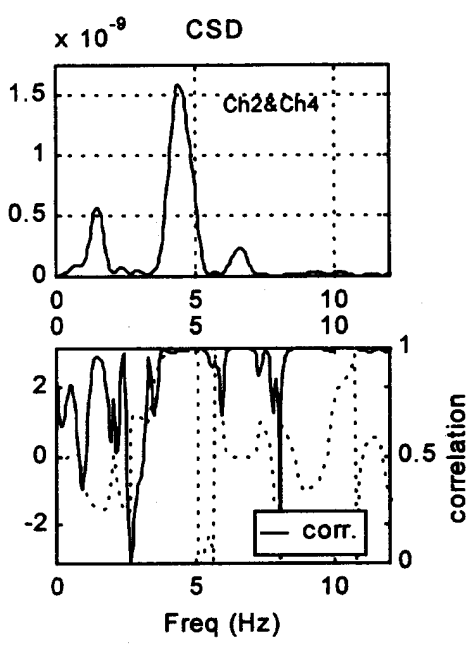

(c)

Fig.6 Cross-spectra and corresponding coherency and phase difference angle (EW).

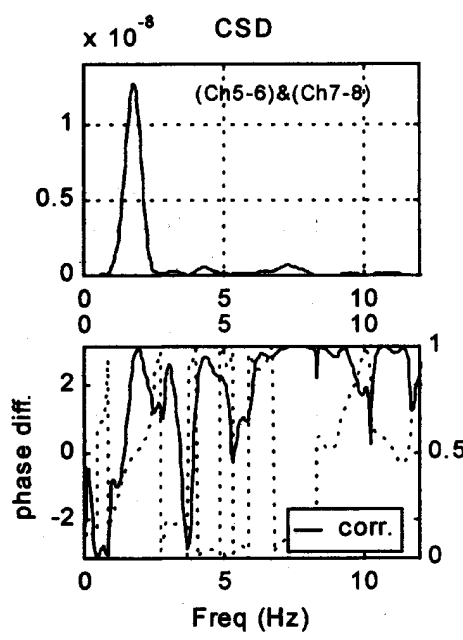

(a) Torsion

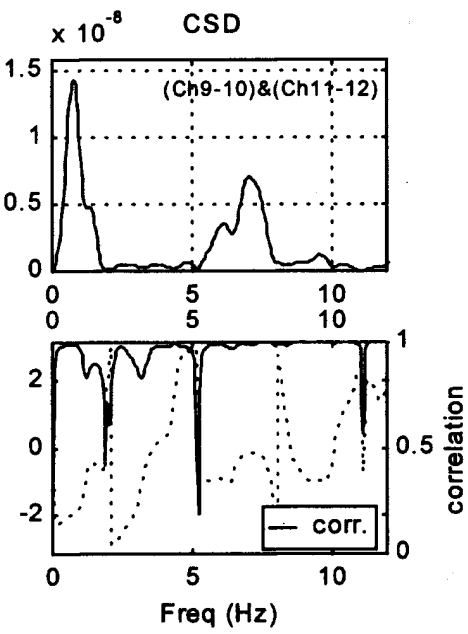

(b) Rocking

Fig.7 Cross-spectra and corresponding coherency and phase difference angle (torsion and rocking).

\subsection{Spectral analysis}

To identify the resonance frequencies of the building for different motions, one can use the cross-spectrum density function. As Bandat and Piersol suggested ${ }^{7}$, the cross-spectrum magnitude and phase, along with coherency function, provide sufficient information to identify the desired frequencies of the mode of the structure. The peaks in the cross-spectrum magnitude are present either in the peaks of the excitation spectrum or in the frequency of the modes. For lightly damped mode, all points on structure response will be either in-phase or $180^{\circ}$ out of phase. For the peaks due to the excitation, the phase will be usually something other than zero or $180^{\circ}$. The cross-spectral density function is calculated using Welch's average periodogram method and then windowed by 512 points.

Base on the above explanations, in the following parts the resonance frequencies of the building due to different motions will be clarified.

\section{Translational motion}

From the magnitude of the cross-spectrum density of $\mathrm{Ch} 3$ and $\mathrm{Ch} 4$ (Fig.5a), it is clear that at $1.36 \mathrm{~Hz}$, the coherency is one and the phase difference is about zero. Also from the magnitude of the crossspectrum density of $\mathrm{Ch} 4$ and $\mathrm{Ch} 8$ at this frequency (Fig.5b), the coherency is one and phase difference is near zero. This concludes that the $1.36 \mathrm{~Hz}$ is the frequency of the first mode in NS direction. The second mode can be clarified from $\mathrm{Ch} 2$ and $\mathrm{Ch} 4$ 's cross-spectrum (Fig.5c). At $4.98 \mathrm{~Hz}$ the coherency is one and the phase difference is $180^{\circ}$. Also from cross-spectrum of $\mathrm{Ch} 4$ and $\mathrm{Ch} 8$, at this frequency the phase is zero, which clearly shows the second mode.

In EW direction, from cross spectrum of $\mathrm{Ch} 3$ and $\mathrm{Ch} 4$, and $\mathrm{Ch} 4$ and $\mathrm{Ch} 8$, that concluded $1.56 \mathrm{~Hz}$ is the fundamental mode (Fig.6a\&b). Considering the cross-spectrum of $\mathrm{Ch} 2$ and $\mathrm{Ch} 4$ at $4.49 \mathrm{~Hz}$, where the coherency is one and the phase difference is $180^{\circ}$ (Fig.6c) and from $\mathrm{Ch} 4$ and $\mathrm{Ch} 8$ the coherency is one and the phase is zero, it is clear that $4.49 \mathrm{~Hz}$ is the frequency of the second mode.

Based on the above results, it can be noted that in NS direction, the ratio of the frequency of the second mode to the first mode is about 3.66 and in the EW direction this ratio is almost three. This suggests that in longitudinal direction (EW), the building can be model like a shear beam, but in the transversal direction (NS), a shear-bending model is needed for time history analyses.

\section{Torsional motion}

The torsional motion is also observed in the response of the building. From cross-spectrum density of torsional motion on the roof (Ch7-Ch8) and that of the $1 \mathrm{~F}(\mathrm{Ch} 5-\mathrm{Ch} 6)(\mathrm{Fig} .7 \mathrm{a})$, at $1.85 \mathrm{~Hz}$ the coherency is one and the phase difference is zero, which define 

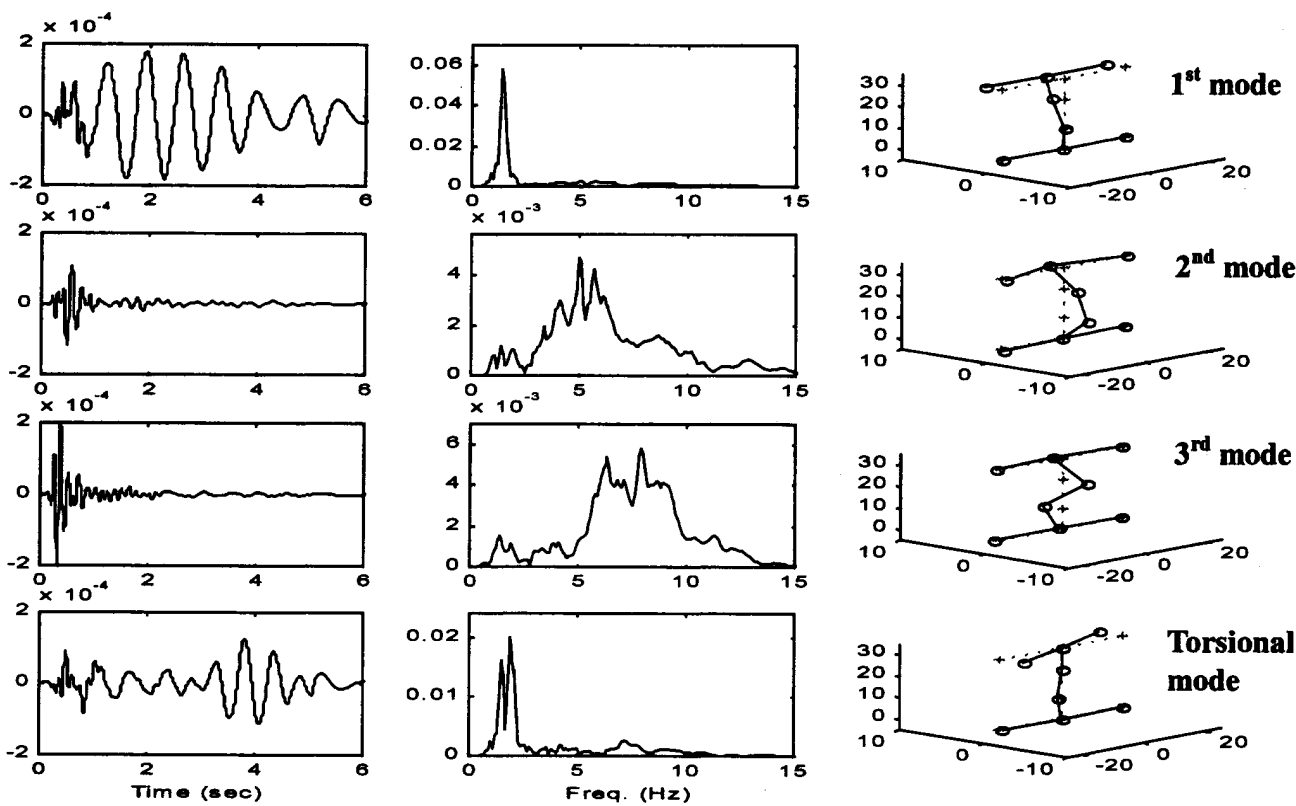

Fig.8 Variation of modes amplitude, corresponding Fourier spectra and mode shape. (Case-A)
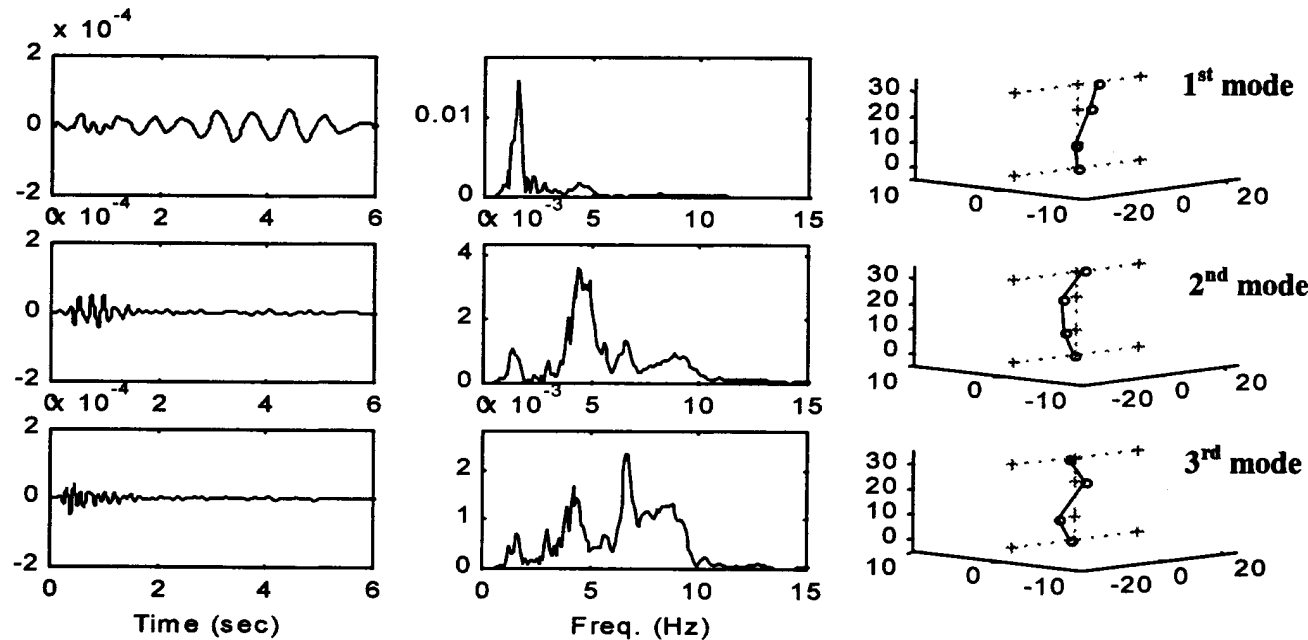

Fig.9 Variation of modes amplitude, corresponding Fourier spectra and mode shape. (Case-C)
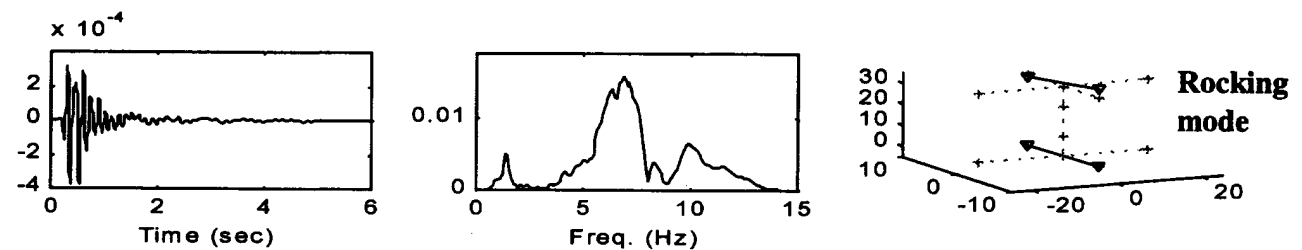

Fig.10 Variation of rocking mode amplitude, corresponding Fourier spectrum and mode shape. (Case-A)

the torsional mode.

\section{Rocking motion}

As discussed before, the rocking motion exists in the building's behavior. By calculating the cross-spectrum density of the relative vertical motion of $1 \mathrm{~F}$ and the roof, at the frequency of $7.2 \mathrm{~Hz}$, the coherency is one and the phase is zero, which shows the first rocking mode in the building (Fig.7b). The bending deformation of the superstructure is calculated from the relative vertical displacement of the roof (Ch11-Ch12) and $1 \mathrm{~F}$ (Ch9-ch10). The maximum vertical displacement due to rocking motion is $2.2 \times 10^{-2} \mathrm{~cm}$ at $1 \mathrm{~F}$ and $7.90 \times 10^{-2} \mathrm{~cm}$ for the roof, when divided by the distance of the vertical sensors $(12.5 \mathrm{~m})$, these deformations are $1.76 \times 10^{-5}$ radians and $6.32 \times 10^{-5}$ radians, respectively. At zero $\mathrm{Hz}$ the phase is other than zero, which can be attributed to the error of sensor correction during data analysis. The peak at around $0.7 \mathrm{~Hz}$ has phase other than zero or 180 , but at $1.36 \mathrm{~Hz}$ the coupling effect with translation is observed. 


\section{Response mode analysis}

The modal response of the building is investigated by means of Response Mode Analysis Method ${ }^{8}$. Having a set of multi-channel simultaneous records, the method decomposes them into orthogonalized components by the eigenvalue analysis of the correlation matrix defined in time domain. The response modes shape are obtained from correlation matrix of the records by:

$\mathbf{C}=\left[c_{i j}\right]$ where $c_{i j}=\mathbf{E}\left[x_{i}(t) x_{j}(t)\right]$

$(\mathbf{C}-\lambda) \mathbf{U}=\mathbf{0}$

Where $U=\left[\begin{array}{lll}u_{1} & u_{2} \Lambda & u_{n}\end{array}\right]$ (mode matrix) and $U$ must be normalized by $U^{T} U=I$. The variations of the amplitude of the $i^{\text {th }}$ response mode $\left(a_{i}(t)\right)$ are calculated by:

$\left[a_{1}(t) a_{2}(t) \Lambda a_{n}(t)\right]=U^{T}\left[x_{1}(t) x_{2}(t) \Lambda x_{n}(t)\right]^{T}$

The displacement motions (integrated from the velocity motions)

Table 2 Modal damping obtained from impactor test.

\begin{tabular}{|c|c|c|c|c|}
\cline { 2 - 5 } \multicolumn{1}{c|}{} & NS & EW & Torsion & Rocking \\
\hline $\begin{array}{c}\text { Damping } \\
(\%)\end{array}$ & 4.52 & 5.51 & 13.33 & 6.88 \\
\hline
\end{tabular}

are also used in this part. For Case-A, the translation (NS) and the torsional motion are considered. The other translation motion (EW) is obtained from Case-C. The rocking motion is separately investigated from records obtained from Case-A. Fig. 8 show the amplitude variation of the first three translation modes in NS and the torsional mode, corresponding Fourier spectra and their mode shape. Fig.9 shows those for translation in EW direction. The rocking mode is shown in Fig.10. The investigated modal frequencies in the previous part conform to the obtained results.

The damping of the first translation modes (NS and EW direction), the torsional and rocking mode are calculated by means of autocorrelation of the obtained variation amplitude waveforms. These dampings are shown in Table 2.

\section{Concluding Remarks}

The dynamic response characteristics of an actual building are investigated by using incident waves generated from an impactor machine. Obtained conclusions are as follows:

1) The impactor machine can be used as a device to generate waves to study the dynamic behavior of the actual building. The wide frequency range $(0-40 \mathrm{~Hz})$, pulse-like wave and reproducibility of this device make it a right tool for this purpose.

2) Frequency of the normal mode for translation, rocking and torsional motion are investigated. Because of wide frequency range of the incident wave, higher modes can be stimulated.

3) The pulse-like shape of the wave generated from impactor makes it possible to observe later arrival torsional response of the building. Also by using this device it is possible to investigate the vertical response of the building?).

4) The non-linearity characteristics of the structure due to the damage from the previous earthquake (namely 1978.6.12),affects the frequencies of the modes of the structure subjected to lowlevel and high-level amplitude of the incident waves. For the low-level amplitude incident wave, higher resonance frequency is obtained. The deterioration of the structural materials can be investigated by lengthening of the period of the structure.

Based on the obtained results, an analytical model can be made to simulate the dynamic behavior of the building. The torsional response must carefully investigate at this stage to explain the beat phenomenon.

\section{Acknowledgment}

The work reported herein is the partial result of a project supported by Science Foundation of Ministry of Education through Grant No.11650573. The authors would like to express their gratitude to Professor Akira Hasegawa of Observation Center for Prediction of Earthquake and Volcanic Eruptions of faculty of science of Tohoku University, for providing the impactor machine to perform the test. We also thank Taeko Sugimoto for her efforts to perform the test and data aquisation.

\section{References}

1) Specifications of LSS-6 Land Air Gun impactor, Bolt Technology Corporation.

2) M. Nasu, H.Haya: Effect of Uneven Thickness of the Soft Ground on Earthquake Damage to Building, QR of RTRI, Vol.31, No.4, 1990.

3) T.Shiga et al.: Dynamic properties and earthquake response of a 9-story reinforced concrete building, 5th WCEE, 1973.

4) T.Shiga et al.: Observation of strong earthquake motions and nonlinear response analysis of the building of Architecture and Civil Engineering Department, Tohoku University, Transactions of AIJ, No.301, pp.119-129, 1981. (Japanese)

5) K. Fujihashi: Investigation on vibration characteristics and evaluation of seismic resistance of the building of the Department of Architecture and Building Science of Tohoku University, Master thesis, 1998. (Japanese)

6) M. Motosaka: Ground motion characteristics in Sendai area, and structural damage during the 1998.9.15 Miyagiken Nanbu earthquake, Proc. Of 20th year memorial symposium of 1978 Miyagiken Oki earthquake, pp.17-22, 1998. (Japanese)

7) Bendat J.S.\& Piersol A.G: Engineering Applications of Correlation and Spectral Analysis; John Wiley \& Son; 1980.

8) M. Takita et al.: Analysis of three dimensional earthquake response of soil-structure system by response mode analy is method; 12 WCEE, 2000.

9) A.Niousha et al.: Investigation on the vertical vibration characteristics of actual structure for earthquake observation records and impactor test; Tohoku Journal of Natural Disaster Science, No. 35, pp.81-86, 1999.

\section{Appendix}

\section{Ground motion}

The ground motion response is also investigated during the impactor test. The vertical impact load propagates radially outward from the source. The waves composed of body and surface wave (Rayleigh), which the former propagate in a hemispherical wave front and the latter in a cylindrical wave front. The mainly propagated energy is due to Rayleigh wave. Becasuse of geometric damping the amplitude of the wave decrease with distance from source. Due to space limitation only the attenuation result is shown. (Fig.11)

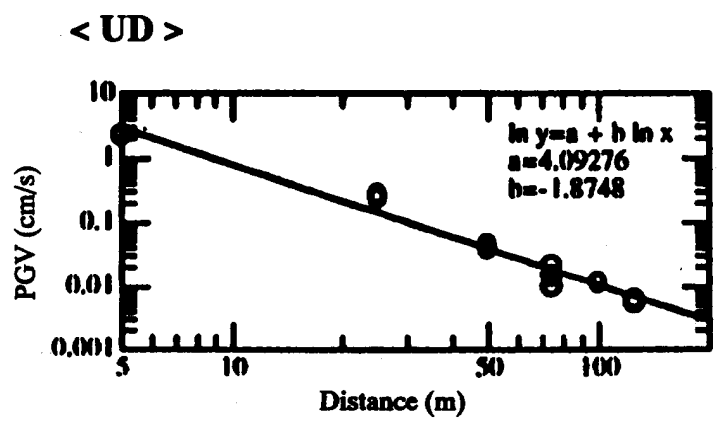

Fig.11 Attenuation of ground motion's amplitude

[2000年 4 月20日原稿受理 2000年 7 月26日採用決宝］ 